\title{
Structure and Hardness Variations Through Section of Hot-Forged Pipe Billet from PT-1M Alloy
}

\section{F. V. Vodolazskiy, S. M. Illarionova, N. A. Barannikova, A. L. Uryadova, and A. G. Illarionov \\ Ural Federal University, 19, Mira str., Ekaterinburg, Russian Federation}

\section{Abstract}

In this paper structure and hardness variations through the section of the hot-forged pipe billet from the PT-1M alloy were studied by the methods of macro, micro, X-ray structural and durometric analyzes. A coarse nonuniform structure through sections of the pipe billet and the relationship between the structure and the hardness were established.

Keywords: titanium alloy PT-1M, hot deformation, macrostructure, microstructure, hardness.
Corresponding Author:

F. V. Vodolazskiy

f.v.vodolazskiy@urfu.ru

Received: 25 February 2019

Accepted: 9 April 2019

Published: 15 April 2019

Publishing services provided by

Knowledge E

(c) F. V. Vodolazskiy et al. This article is distributed under the terms of the Creative Commons Attribution License, which permits unrestricted use and redistribution provided that the original author and source are credited.

Selection and Peer-review under the responsibility of The Ural school-seminar of metal scientists-young researchers Conference Committee.

\section{Intorduction}

PT-1M is a low-alloyed $\alpha$-alloy of titanium of the Ti-Al system, which have a high corrosion resistance in sea and fresh water and widely used for the production of pipes in shipbuilding [1]. Initial stages of pipe production often include hot deformation in the $\beta$ phase region. That is why a large-sized hot-forged pipe billet [2] may have grain structure heterogeneity through the sections [3], which affects on the mechanical properties, hardness in particular. In this paper structure and hardness variations through the section of the hot-forged pipe billet from the PT-1M alloy was studied.

\section{Research Material and Methods}

The material for the study was templates of a segment of $1 / 4$ of a circle cut from a hotforged pipe billet with a diameter of $188 \mathrm{~mm}$ (reduction ratio 4,6) from PT-1M alloy. The chemical composition of the alloy was Ti-0.4Al-0.080, wt. \% within the alloy grade [4] and it had qualified mechanical properties [2]. The following types of analysis were used: 
macrostructural - visually using the scale method [5], microstructural - using an OLYMPUS GX51 microscope, X-ray difraction analysis (XRDA) - using a Bruker D8 Advance diffractometer (Cu $\mathrm{K}_{\alpha}$-radiation), and micro-Vickers hardness according to GOST 6507-1 2007 [6] on a Zwick / Roell ZHU type 6187-5 LKV universal hardness tester. The analysis was performed on the transverse and longitudinal sections of the templates after the etching in a $15 \%$ solution of hydrofluoric acid for macrostructure and in an water solution of nitric and hydrofluoric acids in a ratio of $2 \% \mathrm{HF}+4 \% \mathrm{HNO}_{3}+94 \% \mathrm{H}_{2} \mathrm{O}$ for microstructure in accordance with the recommendations of the monograph [7].

\section{Results and Discussion}

The macrostructure of hot- forged billet of alloy PT-1M in the longitudinal and transverse direction is presented on fig. 1 .

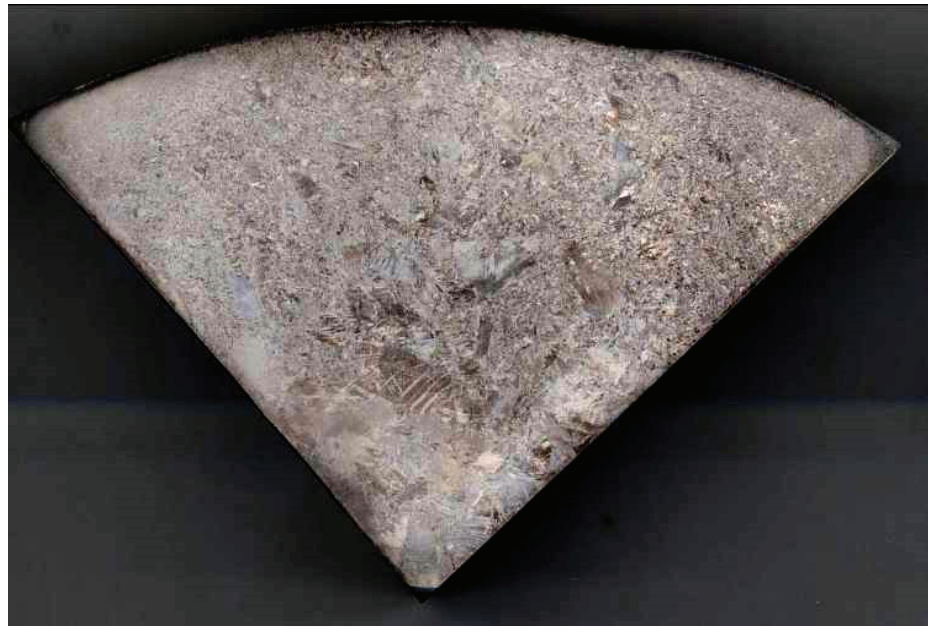

$a$

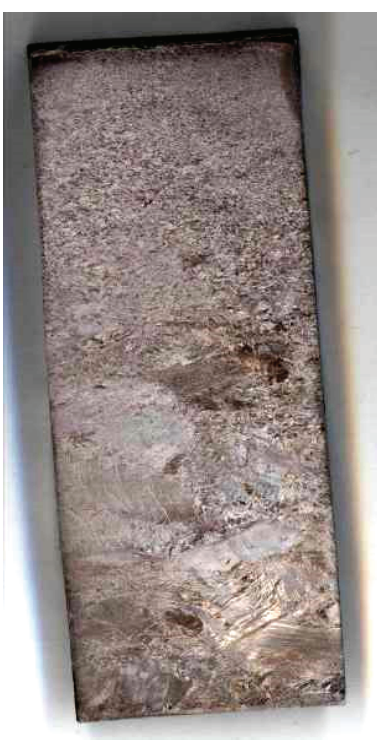

$b$

Figure 1: Macrostructure of the PT-1M alloy templates in the cross-section (a) and longitudinal section (b) (without magnification).

Analysis of the macrostructure of the pipe billet showed that it is not uniform across the section of both the transverse and longitudinal templates (Fig. 1) and has the 23rd grain score at the outer surface, according to the macrostructure scale of titanium alloys [5], which gradually increases up to 10 score to the center. The grain size in the center of the template is about $8-10 \mathrm{~mm}$. Visible macrostructure defects were not found. The difference of grain size indicates about an incomplete processing of the grain structure of the semifinished product in the section of the template during its 
deformation processing, which may be occurs due to the relatively small reduction ratio (according to the supplier of about 4.6) during pipe billet production.

The analysis of samples obtained from cut near the center (1/4 of the radius), $1 / 2$ of the radius and near the surface of the template are shown in Fig. 2. There are only lines of $\alpha$-solid solution on the diffractograms, which is typical for $\alpha$-alloys, which do not contain $\beta$-stabilizers as alloying elements. The lattice parameters of the $\alpha$-phase, determined after shooting in different sections, are almost the same: $\mathrm{a}=0.2948 \pm 0.0001 \mathrm{~nm}, \mathrm{c}=$ $0.4682 \pm 0.0001 \mathrm{~nm}, \mathrm{c} / \mathrm{a}=1.588$. The obtained values of the $« \mathrm{c} / \mathrm{a}$ » parameter of the $\alpha$-phase are slightly higher than of pure titanium (1.587) due to the aluminum alloying [8].

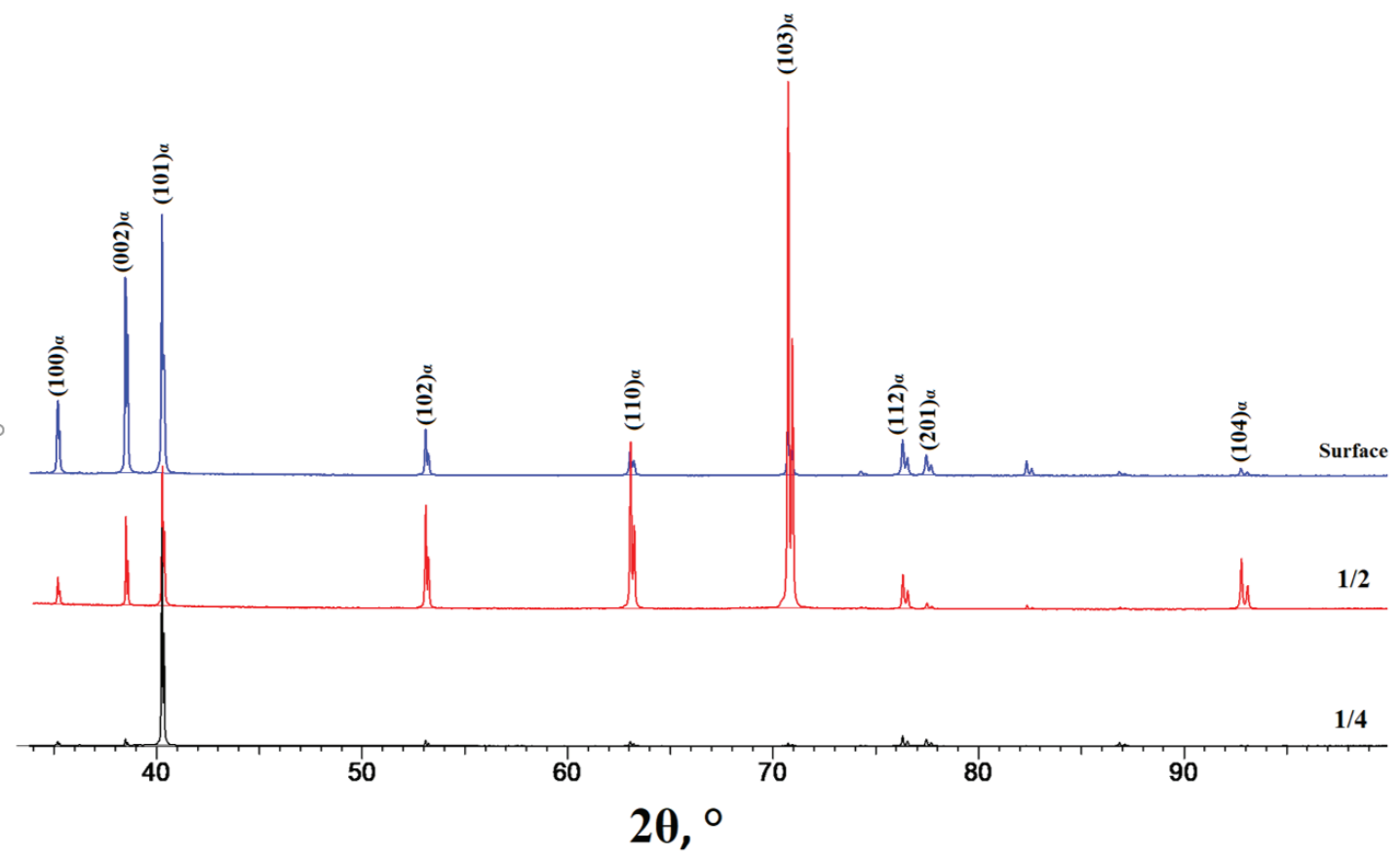

Figure 2: Diffractograms from $1 / 2,1 / 4$ of the radius, and near surface area of the PT-1M alloy.

The intensity ratios of the $\alpha$-phase lines on diffractograms from different sections of the pipe billet are very different. The diffractogram of central template (1/4 of the billet radius) has one line $\left(101_{\alpha}\right)$ that are much higher than others. This effect we associated with a coarse nonuniform grain structure. This effect is much stronger in the central areas of the pipe billet (see Fig. 1).

The microstructures of the PT-1M alloy from the cross-section of the template is shown on Fig. 3.

There are coarse grain structure in the central part and at $1 / 2$ of the cross section of the template, grain size can reach several millimeters (Fig. 3, a), which was also observed above (Fig. 1). Large $\alpha$-plates are located inside the grain. In the central part of the template, the formation of smaller recrystallized grains in some areas between large 


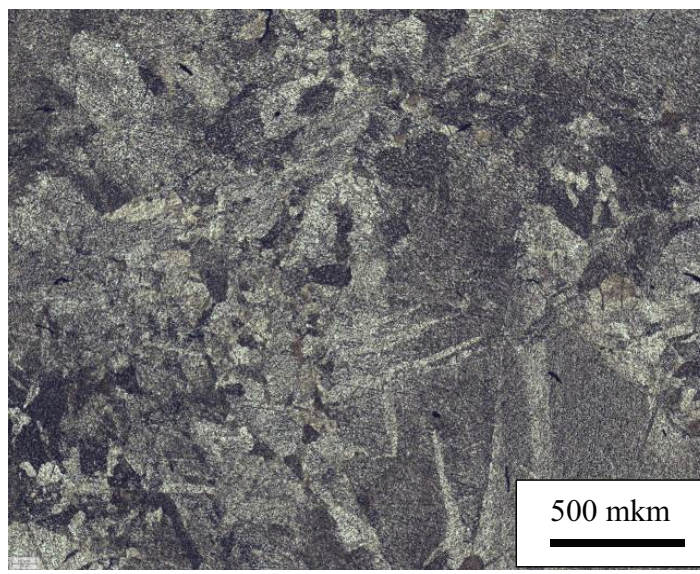

$a$

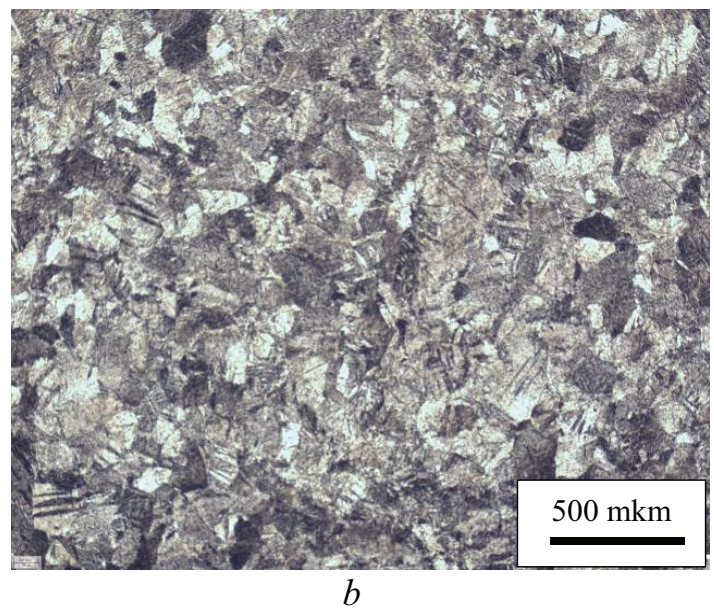

Figure 3: Microstructure of the PT-1M alloy from the cross-section of the template closer to the center (a) and on the outer surface (b).

grains is observed (Fig. 3, a). This structure we can refer to 8-9 type according to the scale of microstructures for $\alpha$-alloys [7], which is the coarse-grained plate structure with clearly defined $\beta$-grain boundaries formed after deformation of the alloys in the $\beta$-phase region and subsequent heat treatment in the the $\beta$-phase region. In our case, the heat treatment in the $\beta$-phase region was not carried out, this structure can be formed during slow cooling of large-sized pipe billet after forging.

The structure of near surface area is characterized by the formation of a fine grains compared to the central part and $1 / 2$ of the cross section of the pipe billet. This grains have an equiaxial form with annealing twins (Fig. 3, b) which is typical for recrystallized grains. Its grain size is much more smaller than in the center of template and is about 100-500 microns. This structure we can refer to 3rd type according to the scale [7], which is formed after deformation and recrystallization at the temperature of $\alpha$-phase region [5]. Probably the reason for such a difference in the structure near the surface and at the center of the template is cooling-down the surface of pipe billet by forged tool. As a result, the near surface area get bigger strain-hardening during forging compared with inner areas, which leads to the development of recrystallization processes of $\alpha$-phase. This is also facilitated by relatively slow cooling of large-sized billet from the deformation temperature.

The measurement of Vickers hardness was carried out in three radius of the transverse template with a measurement interval of $5 \mathrm{~mm}$. The measurement results are shown in Fig.4. A general analysis of hardness values shows that it ranges from 135 $\mathrm{HV}$ to $178 \mathrm{HV}$, while the average value is $150 \mathrm{HV}$, and the calculated spread of values from the average is $\pm 10 \mathrm{HV}(\alpha=0.05)$. 


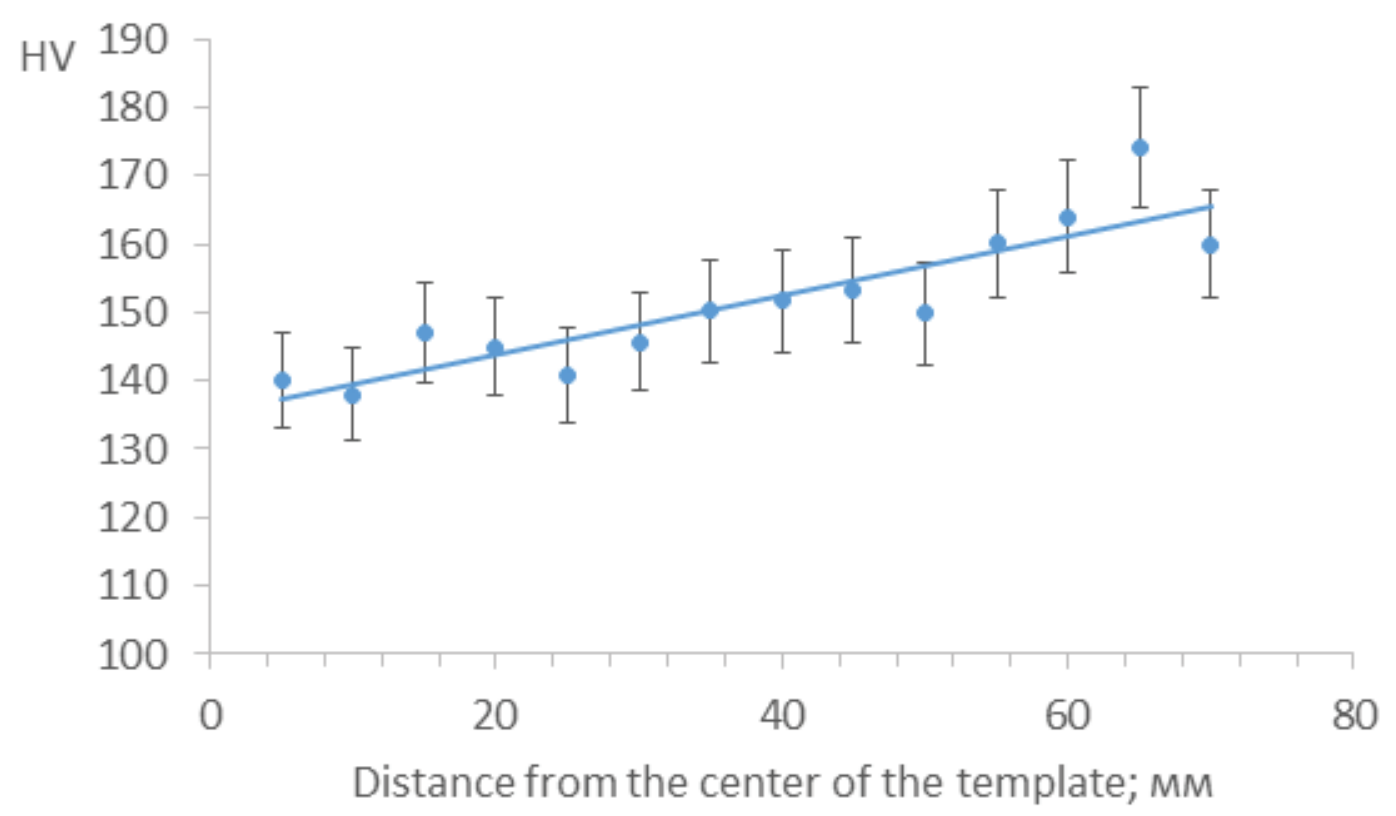

Figure 4: The change in hardness from the center to the outer surface.

The use of linear approximation of the obtained values (Fig. 4) showed that there is a tendency to increase in hardness from the center of the template to its surface. The reason for this is higher grain size in the center compared with the near surface layers (see Fig.1, 3).

\section{Conclusion}

The study of a hot-forged pipe billet with a diameter of $188 \mathrm{~mm}$ from PT-1M alloy showed that there were not uniform macro- and microstructure through sections. The most coarse-grained structure was in the center of pipe billet with a 10 grain score and 8-9 type according to the scales of macro- and microstructures ( $\alpha$-alloys), respectively. This led to a different intensity ratio of $\alpha$-lines on diffractograms through different sections of the billet, and resulted to the hardness increase from the center to the surface of the billet from 140 to 165 Vickers.

The study was supported by Russian Science Foundation, grant 18-79-10107. 


\section{References}

[1] S.S. Ushkov, A.S. Kudryashov, E.A. Karasev, Titanium alloys in shipbuilding and marine structures, Titan. 1 (2002). 44-49.

[2] TU 1-5-132-78 Pipe blanks of titanium alloys. Technical conditions. Verhnyaya Salda, VSMPO. 1978. 9 p.

[3] V.K. Aleksandrov, Semi-finished products from titanium alloys, M.: ONTI VILS 1996, $584 \mathrm{p}$.

[4] OST 1 92077-91 Titanium alloys. Stamps M.: VILS. 1991. 4 p.

[5] L.A. Nikolsky, Hot stamping and pressing of titanium alloys, M.: Mashinostroenie, 1975, $285 \mathrm{p}$.

[6] GOST 6507-1 2007 Metals and alloys. Vickers hardness measurement. Part 1. Method of measurement. M.: Gosstandart. 2007. 19 p.

[7] S.G. Glazunov, B.A. Kolachev, Titanium alloys. Metallography of titanium alloys, M.: Metallurgy, 1980. 464 p.

[8] U. Zwicker Titan and its alloys, M.: Mir. 1979. 512 p. 